\section{THE OPENING OF THE MEDICAL} SESSION

THE beginning of October always sees the opening of the medical session, and introductory addresses have been delivered at many of the Lomdon and provincial schools. At others, however, the session opened without formality.

At University College Prof. Norman Collie, F.R.S. delivered the introductory address, taking for his subject the relation of chemistry to medicine. He said that it is now more than ever imperative that medical men should have a good grounding in chemistry, and he directed attention to the numerous instances in which chemistry has a bearing on medicine. The question of the action of ferments, of great importance to the medical man, must uitimately be answered by the chemist. The physiological action of toxines and antitoxines has for some time largely engaged the attention of medical science, but it will probably be the chemist, after he has determined their molecular structure, who will be able to explain how and why they are produced. In the process of the assimilation of food the changes that occur are purely chemical. The composition of the various secretions also can only be arrived at by an analysis in a chemical laboratory.

At King's College the session was opened with an address by Dr. Thomas Buzzard, F.R.S., on the future relation of King's College to its medical school and hospital. After a few words of welcome to new students, and impressing on his audience the value of the degrees of the University of London, he briefly sketched what will be the position of college and hospital when the latter has been removed to Camberwell. It is intended that the two should be distinct, the preliminary and intermediate studies being pursued at the college, the subsequent more purely medical studies at the hospital. At the same time the two will be autonomous, and there will be no obligation on a student who completes his preliminary studies at the college to pass on to King's College Hospital; he will be at liberty to go where he pleases. In order to carry out this separation, composition fees will be abolished, and no member of the hospital staff will be permitted to teach any preliminary or intermediate subject at the college.

Dr. A. E. Wright, in the opening address at St. Mary's Hospital, emphasised the importance of research and the need for the provision of adequate salaries for scientific workers.

Dr. F. J. Wethered, in his address on practice and theory in medical study at the Middlesex Hospital, also spoke of the need for the endowment of chairs in the University of London. He pointed out that medicine is not only a science, it is a practical art, and no amount of theoretical knowledge can replace study and observation in the wards and out-patient room.

At Charing Cross Hospital the opportunity of the opening of the session was taken for the delivery of the Huxley lecture. The lecturer this year was Sir William MacEwen, who prefaced his remarks with some allusion to the lifework of Huxley before passing on to his subject, "The Recent Advances in Science and their Bearing on Medicine and Surgery."

Prof. Alex. Macalister, F.R.S., was the lecturer at St. George's Hospital, and delivered an instructive address on "The Evolution of the Medical Curriculum."

At the London (Royal Free Hospital) School of Medicine for Women, and at the Royal Veterinary College, the sessions were opened by Miss Murdoch and by Prof. Brodie, F.R.S., respectively.

\section{THE EDUCATION OF A CHEMIST. ${ }^{1}$}

THE education of a chemist (and the word " chemist," of course, includes the qualification "technical chemist") must be conceived in the sense that it consists in an effort to produce an attitude of mind, rather than to instil definite knowledge. Of course the latter must not be neglected; the definite knowledge may be likened to the bricks which the architect has at his disposal in erecting a beautiful building; he knows their shapes, their capacity

I From an address delivered before the Society of Chemical Industry, at New York, September 8, by the president, Sir William Ramsay, K.C.B.,

NO. I 823 , VOL. 70$]$ for resisting stresses, and, in short, what can be done with them. But the conception of the design is the result of many attempts to create; just as the poet has to utilise words, or the architect bricks, so the chemist has to know the materials with which he is dealing. The training of a bricklayer, however, will never make a man an architect; nor will the dry research of a grammarian train a poet. In short, it is the inventive faculty which must be cultivated.

Now how can this be brought about? The answer is perfectly simple: by offering examples. Every teacher in the laboratory, from senior professor to junior assistant, must be engaged in research, and, most important of all, they must not be reticent, but willing to converse freely on their problems. It is that which creates a " chemical atmosphere."

The qualities tested by such examinations as have been customary for the past forty years in England are the last which one would wish to have in a student of sciencereadiness of memory, to the exclusion of deliberate judg ment; the faculty of spreading knowledge thin, and making a veneer of scientific facts instead of the power to correlate them and increase their value; and the skill to gauge the capacity of and hoodwink the examiner, instead of the power to incite enthusiasm in others. They are ideal qualities for a successful barrister, because they pay in his profession; but their reward has been the bane of science. A sound judgment, though it may be a slow one; persistence in struggling against obstacles; the knowledge where to get information when required, and to use it when found and the inventive faculty-these are the qualities required, and they can be gauged only after long-continued observation. Moreover, the pernicious system of competitive scholarships and fellowships, instead of eleemosynary support given to the necessitous and deserving youth, has also contributed much to the debasement of the scientific spirit; for it has early implanted in the young mind the idea that to outrun his fellows, and to work solely for a money reward, are the ends to be aimed at, instead of the joy of the exercise of a divine gift, and the using that gift for the benefit of man.

The ideal plan of education for technical chemists would be some system analogous to the apprenticeship of engineers, after they have been educated in the science; that is, after the correct habit of mind has been largely formed. But it is difficult to see how this can be brought about. . The obstacles in the way appear to me to be insurmountable. The chemical manufacturer is not willing to throw open his works to students, nor would he do so even if very considerable premiums were paid. Indeed, in England, it is not uncommon for the "chemist," so-called, to be refused admission to the works, and to be confined to the laboratory. In the larger German works, where many chemists are employed, it is possible for a young man to gain the requisite experience. I have been informed by the managing director of a chemical works in Germany where seventy chemists are employed that nature has divided the young men into three large classes, the members of which are fairly easily distinguished and do not greatly overlap. There is first the routine chemist, the young man who declines responsibility, but who is hardworking and trustworthy; he finds his place as an analyst, testing raw materials and analysing the products at various stages, including the finished products. Second, there is the young man to whom the management of some department may be entrusted; one with a firm will, plenty of energy, and the quality of governing men. And third, there is the research chemist, who delights in new problems, whether suggested by others or conceived by himself. All three classes are utilised; and after serving as analysts for some time, the young men naturally range themselves in one or other department, where their natural tendencies find scope. But even in Germany the number of works which employ seventy chemists is not great, and with a small number it is more difficult to effect the division of labour so satisfactorily.

In conclusion, let me make one more remark. It is that the scientific curiosity of to-day often becomes the trade necessity of to-morrow. A scientific friend of mine once directed my attention to the fact that most of the changes which have been introduced in industry have had their origin in the universities. Why? Because the investigator is un- 